\title{
Evaluation of Supply Chain Using Hierarchical Analysis
}

Submitted 23/02/19, 1st revision 15/04/19, 2nd revision 18/06/19, accepted 22/07/19

\author{
Venera Maratovna Timiryanova ${ }^{1}$
}

\begin{abstract}
:
Purpose: The paper is aimed at extending the ideas about the functioning of distribution networks. The main objective of the research is to determine the extent to which the development of wholesale trade within the central places of the region and the incomes of the population have an impact on the volume of shipped goods in municipal areas.

Design/Methodology/Approach: Hierarchical linear modeling (HLM) is used in this article. This method defines group and intergroup variation taking into account the multi-level nature of the processes. The variation in the volume of products shipped in municipalities is considered as a result of the influence of the factors at two levels: population incomes (municipal level) and wholesale trade turnover (regional level). The research is conducted on data obtained from 331 municipalities located in 7 constituent entities of the Russian Federation.

Findings: The relevance of the constructed model indicates the possibility of application of the hierarchical analysis methods in the sales chain research. For 7 subjects of the Russian Federation under consideration, it was found that the role of distribution networks is small.

Practical Implications: It is determined that in order to promote products it is required to pay attention to the role of the wholesale link in the development of production of the territories in question. The use of hierarchical analysis in market research makes possible to apply a balanced approach to the creation of favorable conditions in the development of public and private programs for market infrastructure development.

Originality/Value: The use of hierarchical analysis methods in the research of sales chains expands the understanding of their functioning, since, unlike others, it makes possible to take into account the impact of the factors at several levels of their formation.
\end{abstract}

Keywords: Supply chain, hierarchical linear modeling, distribution, wholesale, production, multilevel process.

JEL codes: $R 12$, R5, 8 D51, F14.

Paper type : Case Research.

${ }^{1}$ Corresponding author, Bashkir State University, Faculty of Economics, 79174073127@mail.ru 


\section{Introduction}

The activity of any manufacturing enterprise is determined by the volume and conditions of marketing. However, the search for buyers is actually not as simple as it seems. As noted by scientists, "small- and medium-scale producers have great difficulty in accessing market outlets", "large buyers face logistics and information obstacles" (Ge et al., 2018). Many studies are aimed at determining the most effective path of motion of products from producers to consumers (Wu et al., 2015; Zhang et al., 2017; Mittal et al., 2018). The reason is that "a supply chain, an interrelating network of suppliers, manufacturers, distributors, and customers, plays an important role in competitive markets to satisfy customer demands" (Sadigh et al., 2013).

This research adds to existing body of literature on supply chain assessment tools. The novelty of this research is the use of the hierarchical linear modeling (HLM) method enable to analyze the interregional differences within the sales chain and determine the extent to which the differences in production volumes in the municipalities are related to the differences in wholesale turnover at the regional level. The purpose of the research is to determine the impact of the wholesale link and the household income on the volume of production using the methods of hierarchical analysis. The hypothesis is based on the assumption that consumption and production at the level of municipalities are associated with the wholesale turnover, which is formed in the framework of central places (Philbrick, 1982; Masai, 1962), usually covering the territory of the region.

In the author's opinion, the results of the research are of interest both to intermediary wholesale enterprises and to government agencies that determine the direction of development of the territories. This applies not only to the countries with a planned economy, where the distribution channels are controlled by the special ministry (Luk, 1998; Deloitte, 2015). Federal/state/municipal authorities are the actors in the system, determining the functioning of supply chains (Hesse and Rodrigue, 2004). The supply chain analysis using the hierarchical analysis methods improves the quality of decision-making for various stakeholders.

\section{Literature Review}

The main prerequisite for the use of hierarchical linear modeling methods is the nested, hierarchically related nature of various processes.

The process of production, distribution, exchange, and consumption is of a sequential nature, often presented in the form of a chain. In various studies, the chain may be of different lengths, but its main components remain unchanged: procurement $\rightarrow$ production $\rightarrow$ distribution $\rightarrow$ consumption $\quad$ (Sheu, 2003; Maye and Ilbery, 2006). Milligan notes that the goods are efficiently provided on a hierarchical 
basis (Milligan, 1984). Chakraborty et al. (2018) indicate the hierarchical nature of the relationship between the suppliers and the customers. Sadigh notes that the coordination of all supply chain parts is a multilevel process (Sadigh et al., 2013). Thus, the sequence (production $\rightarrow$ distribution $\rightarrow$ consumption) has all the properties of a hierarchy in which the results of a subsequent level depend on the activities of a higher level.

The market is also hierarchically connected. First of all, it is necessary to note the theory of central places, which formed the basis of the research on the hierarchy of nodal places (Philbrick, 1957; Masai, 1962), areal functional organization (Kirk, 1969), classifications of land uses (Pissourios and Lagopoulos, 2017). The concept of nested sets of hexagonal market areas appeared, in the framework of which the influence of warehouse location on ordering and operating costs was considered (Bogataj, 1996). It is noted that this is a hierarchical system (Mesarovich et al., 1972; Domanski, 1981). Despite the foregoing, the methods of hierarchical analysis are still poorly used in the analysis of the location of production, wholesale enterprises, and consumers. The work of Chakraborty et al. (2018) can be noted, in which, using the methods of hierarchical analysis, production networks are investigated based on the surveys of firms about their five largest suppliers and the top five customers (Chakraborty et al., 2018). More often, scientists simply build the maps reflecting the distribution of industrial, wholesale enterprises with the determination of the levels and relationships (Philbrick, 1957; Maye and Ilbery, 2006; Ge et al., 2018).

Given the hierarchical nested nature of the data, the existing relationships (production $\rightarrow$ distribution $\rightarrow$ consumption) can be considered at two levels taking into account their areal functional organization. If production and consumption can be identified at the level of municipalities, then distribution can be determined as the general variable for the municipalities at the regional level.

\section{Data and Methods}

In the framework of this research, the hierarchical linear modeling (HLM) method is used, which is actively developing due to the works of Goldstein (2010) and Garson (2013). It is used to research not only social relations but also economic processes (Chan et al., 2010; Yusupov et al., 2019; Lawson et al., 2019). This method makes it possible to link production, distribution, and consumption within the full random coefficients regression model. This model contains the indicator of the volume of shipped goods, works, and services produced by the enterprise (P), as a dependent variable characterizing the production. The organization of the distribution network is characterized by wholesale turnover (D). The purchasing power (consumption) is measured using the average monthly salary of the employees of the enterprises $(\mathrm{C})$. The model tests the proposition that the mean (intercept) for $\mathrm{P}$ is a random effect of the region and of $\mathrm{D}$ at level 2, and $\mathrm{C}$ at level 1: 
Level 1 (lower):

$$
P_{i j}=\beta_{0 j}+\beta_{1 j} \cdot C_{i j}+r_{i j}
$$

Level 2 (upper):

$$
\begin{gathered}
\beta_{0 j}=\gamma_{00}+\gamma_{01} \cdot D_{j}+u_{0 j} \\
\beta_{1 j}=\gamma_{10}
\end{gathered}
$$

where $P_{i j}$ is the volume of shipped goods, works, and services produced by the enterprise per 1 person in the $i$-th municipality of the $j$-th region of the Russian Federation, in thousand rubles; $D_{j}$ is the wholesale turnover, on average per 1 person of the $j$-th region of the Russian Federation, centered around the grand mean; $C_{i j}$ is the average monthly salary of employees in the $i$-th municipality of the $j$-th region of the Russian Federation, centered around the group mean; $\gamma_{00}$ is the general intercept for all municipalities; $\gamma_{01}$ is the linear slope of the predictor $\mathrm{D}_{\mathrm{j}} ; u_{0 j}$ is the error of interregional variance that explains differences between region values of indices achieved by their constituent municipalities; $\beta_{1 j}$ is the regression coefficient (slope) of $\mathrm{C}$ equal to the constant $\gamma_{10} ; r_{\mathrm{i} j}$ is the error of intraregional variance (intermunicipal), explaining the differences between the municipalities within individual regions; represents the error in estimating this indicator within regions; $j$ is the index for affiliation of a municipality to a specific Russian constituent entity, $(j=1,2, \ldots, 7) ; i$ is the index for affiliation to a particular municipality $(i=1,2, \ldots, 331)$.

In this model, the intercept at level 1 is predicted as a random effect of the region and of the level 2 predictor $\mathrm{D}$, which covariate measuring the wholesale trade. As an overall test of whether the RC regression model with predictors is a significantly better fit than the intercept-only (null) model without predictors, the likelihood ratio test can be used. To assess improvement in model fit, the residual variance component is examined. The residual variance component is variance associated with the within-region variation in $\mathrm{P}$ not accounted for by the random effects of the region on the intercept of $\mathrm{P}$ and on the slope of $\mathrm{C}$ and $\mathrm{D}$. As the random effects explain more, the residual component will drop. The research is based on data obtained from 331 municipalities located in 7 constituent entities of the Russian Federation (Figure 1). These constituent entities are on the conditional border between the European and Asian parts of the country, inhabited by 21.9 million people or $14.9 \%$ percent of the country's total population. The main source of the data set is the official website of Federal State Statistics Service (http://www.gks.ru).

\section{Results}

\subsection{Methodological Issues}

The full random coefficients' model is built by the author. The overall test of the model that is reflected in the likelihood ratio test of the difference in deviance (- 
2LL) between models shows that the difference between the current model and the null model is statistically significant (Tables 1 and 2).

Figure 1: The volume of shipped goods, works, and services produced by the enterprise per 1 person within the municipalities in 2017

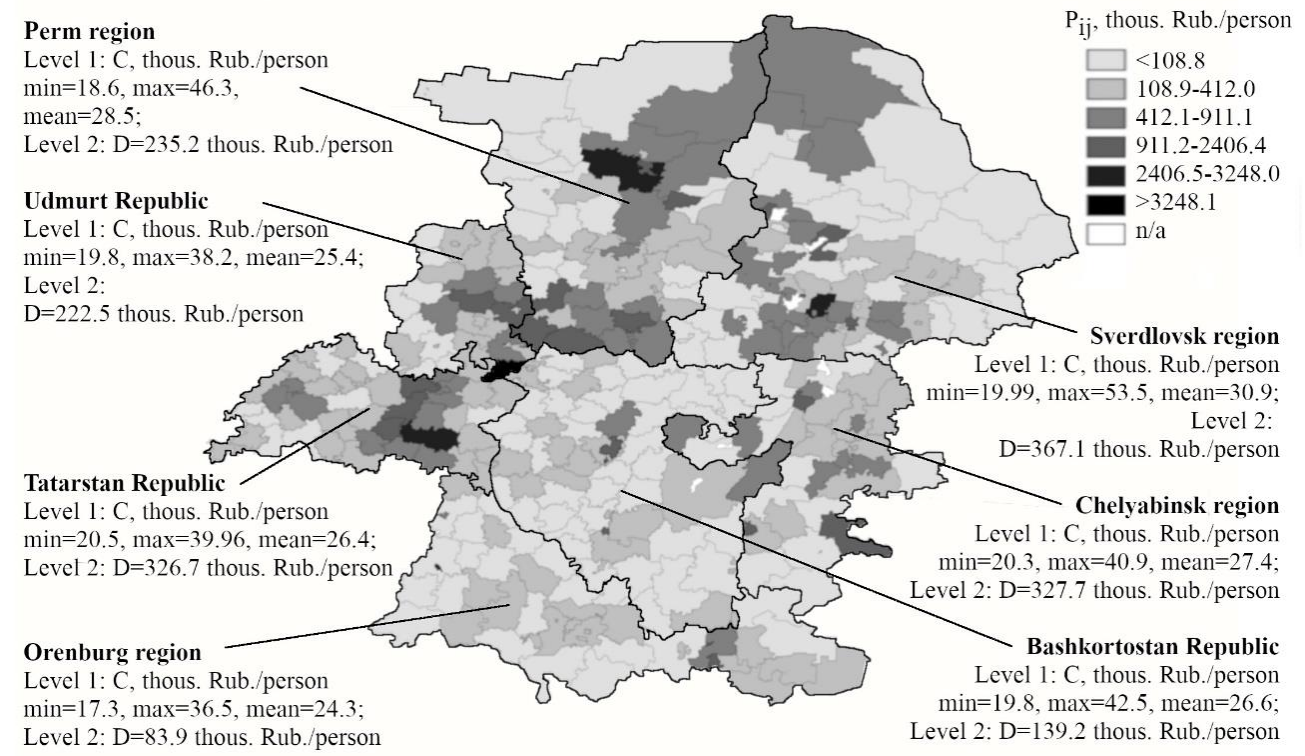

Source: Own elaboration using data from Russian Federal State Statistics Service.

Table 1: Final estimation of variance components

\begin{tabular}{|c|c|c|c|c|c|}
\hline Random effect & $\begin{array}{l}\text { Standard } \\
\text { deviation }\end{array}$ & $\begin{array}{l}\text { Variance } \\
\text { component }\end{array}$ & d.f. & $\chi^{2}$ & $\begin{array}{c}p- \\
\text { value }\end{array}$ \\
\hline \multicolumn{6}{|l|}{ the null model } \\
\hline INTRCPT $1, u_{0}$ & 92.6 & 8566.9 & 6 & 15.2 & 0.018 \\
\hline level $-1, r$ & 520.1 & 270513.3 & & & \\
\hline \multicolumn{6}{|c|}{ the full random coefficients model } \\
\hline INTRCPT1, $u_{0}$ & 88.9 & 7894.6 & 5 & 14.97 & 0.011 \\
\hline level $-1, r$ & 425.7 & 181197.5 & & & \\
\hline
\end{tabular}

Source: Own elaboration using data from Russian Federal State Statistics Service.

In the full random coefficients model, the residual component drops from 270,513.34 in the null model to $181,197.51$ (Table 1). The likelihood ratio test shows this difference to be significant at 0.001 level of significance. The deviance declined by 139.4 points $(5136.8$ - 4997.4) compared to the null model (Table 2). The residual variance is $95.8 \%(181,197.51 /(7894.58+181,197.51)$ of the total variance in the full random coefficients model compared by similar calculation to $96.9 \%$ in the null model. 
Table 2: Final estimation of fixed effects (with robust standard errors)

\begin{tabular}{lcc}
\hline & The null model & The full random coefficients model \\
\hline For INTRCPT1, $\beta 0$ & & $336.3^{*}$ \\
\hline INTRCPT2, $\gamma 00$ & $336.4^{*}$ & $(34.8)$ \\
& $(42.0)$ & $0.6^{* *}$ \\
D, $\gamma 01$ & & $(0.26)$ \\
& \\
\hline For C slope, $\beta 1$ & $51.7^{*}$ \\
INTRCPT2, $\gamma 10$ & $(4.02)$ \\
\hline Reliability estimate & \\
\hline INTRCPT1, $\beta 0$ & 0.59 & 0.67 \\
Deviance & 5136.8 & 4997.4 \\
\hline
\end{tabular}

Note: *significant $<1 \%$. **significant $<10 \%$.

Source: Own elaboration using data from Russian Federal State Statistics Service.

Table 2 shows the fixed effects for all models. Robust standard errors used because of the distribution of the dependent variable were misspecified. $\mathrm{C}$ is a significant predictor of $\mathrm{P}$ and positively impacts the size of $\mathrm{P}$.

In this model all fixed effects are significant. The level 1 intercept in the full random coefficients model of 336.3 gives the mean volume of the products shipped across all municipalities when other variables in the model are controlled at zero. The level 2 predictor coefficient is positive, but low (0.6). It means that the higher the percent $\mathrm{D}$ in the region, the higher the intercept (hence the higher $\mathrm{P}$ ) for municipalities. The slope of the level 1 predictor $\mathrm{C}$ is significant and positive. The fact that it is positive means the more the household income, the higher the predicted volume of production, controlling other variables in the model. The fact that the intercept component is significant even controlling for other variables in the model means that there remains a significant variation, which might be explained by adding additional predictors to the model.

\section{Discussion}

The results are very controversial. The author used hierarchical analysis tools to evaluate the supply chain. The results obtained indicate that wholesale turnover for the considered regions of Russia is insignificant when substantiating the differences in the volume of production. However, a lot of works suggest that it is the wholesale that contributes to the promotion of products in the market and its development is important for manufacturers (Sadigh et al., 2013; Wu et al., 2015; Zhang et al., 2017; Ge et al., 2018; Mittal et al., 2018). In the author's opinion, such results indicate an ineffective organization of the sales chain, which largely retained the shortcomings of the centralized distribution system of goods of the Soviet period. The share of the city of Moscow in the total turnover of wholesale trade in 2018 
accounted for $37.5 \%$. The value is decreasing (for example, in 2009 it was equal to $45.4 \%$ ), but it is still significant.

There are certain flaws in the data structure. In particular, the indicator of the volume of shipped goods, works, and services produced by the enterprise per 1 person in the $\mathrm{i}$-th municipality of the $\mathrm{j}$-th region of the Russian Federation includes both the turnover of spare parts for production and the turnover of goods. At the same time, it is customary to separate the processes of supply of the components for assembly and the distribution of finished products throughout the entire value chain (Sadigh et al., 2013). However, the available data do not allow this. In addition, the estimates were carried out on the basis of data on the volume of goods shipped by large and medium enterprises. This lack of data can lead to the error in the decisionmaking on the placement of objects, as it does not take into account the activities of small businesses.

Despite the defined shortcomings, the author sees the prospects of using the hierarchical analysis methods. The models built are significant; therefore, the hierarchical nature of the data makes it possible to decompose the variation of indicators into several levels within the supply chain. The variety of hierarchical analysis methods makes it possible to build more complex models, for example, the three-level ones. The model can be improved by the inclusion of additional variables.

\section{Conclusions}

A dynamic investigation of the occupancy problems of the distribution centers is carried out both for the benefit of the enterprises, having the goal of maximizing the potential rate of return on facility investment (Sheu, 2003), and state authorities (Hesse and Rodrigue, 2004; Deloitte, 2015). Within the framework of this research, the methods of hierarchical analysis were used to assess the impact of the household incomes (municipal level) and the wholesale turnover (regional level) on the volume of goods shipped. It is determined that the wholesale trade turnover is insignificant for the considered regions of Russia and practically does not affect the production volumes in the municipalities. There is significant intraregional differentiation. The volume of social payments and domestic incomes, which characterizes the domestic demand in the markets, has a positive effect on the volume of goods shipped in the municipalities.

Although this research is a simplified representation of a complex reality, it provides valuable insights into the influence of the factors, given their hierarchical nesting. This reveals new perspectives in supply chain research. The information obtained as a result of such analysis improves the quality of decision-making of various stakeholders. In particular, when: (1) determining the volume of regional investments in infrastructure, both in the public and private sectors, (2) developing the policies and programs promoting regional and local food systems, and (3) 
increasing the efficiency and competitiveness of trade and manufacturing enterprises.

Subsequent research should be focused on testing of this tool using the data obtained from other countries and including additional variables that characterize the functioning of the supply chain.

\section{References:}

Bogataj, M. 1996. Inventories in spatial models. International Journal of Production Economics, 45(1 - 3), 337 - 342, doi:10.1016/0925 - 5273(96)00005 - 9.

Chakraborty, A., Kichikawa, Y., Iino, T., Iyetomi, H., Inoue, H., Fujiwara, Y. \& Aoyama, H. 2018. Hierarchical communities in the walnut structure of the Japanese production network. PLOS ONE, 13(8), e0202739. doi:10.1371/journal.pone.0202739.

Chan, C.M., Makino, S. \& Isobe, T. 2010. Does subnational region matter? Foreign affiliate performance in the United states and China. Strategic Management Journal, 31(11), 1226-1243, doi: $10.1002 / \mathrm{smj} .854$.

Che, Z.H. \& Chiang, C.J. 2010. A modified Pareto genetic algorithm for multi - objective build - to - order supply chain planning with product assembly. Advances in Engineering Software, 41(7 - 8), 1011-1022, doi:10.1016/j.advengsoft.2010.04.001.

Deloitte. 2015. Investment Promotion Report of China's Logistics Industry, Investment Promotion Agency of Ministry of Commerce, P.R. China, Development \& Research Center of the State Post Bureau. Available at:

https://www2.deloitte.com/content/dam/Deloitte/cn/Documents/public sector/deloitte - cn - ps - china - logistics - industry20142015 - en - 150708.pdf.

Domanski, R. 1981. The Optimal Location of Economic Activities in a Hierarchical Settlement System in a Rural Region. IIASA Working Paper. IIASA, Laxenburg, Austria, WP $-81-082.33$ p.

Garson, D. 2013. Hierarchical linear modeling: guide and applications, Wiley.

Ge, H., Goetz, S., Canning, P. \& Perez, A. 2018. Optimal locations of fresh produce aggregation facilities in the United States with scale economies. International Journal of Production Economics, 197, 143-157, doi:10.1016/j.ijpe.2018.01.007.

Goldstein, H. 2010. Multilevel Statistical Models: 4th Edition, Wiley.

Hesse, M. \& Rodrigue, J.P. 2004. The transport geography of logistics and freight distribution. Journal of Transport Geography, 12(3), 171-184, doi:10.1016/j.jtrangeo.2003.12.004.

Kirk, R.J. 1969. Urban - industrial growth potentials in regional economic development. Retrospective Theses and Dissertations, 4666, https://lib.dr.iastate.edu/rtd/4666.

Lawson, B., Potter, A., Pil, F. \& Holweg M. 2019. Supply Chain Disruptions: The Influence of Industry and Geography on Firm Reaction Speed. International Journal of Operations and Production Management, https://doi.org/10.1108/IJOPM - 04 $2018-0225$.

Luk, S.T.K. 1998. Structural changes in China's distribution system. International Journal of Physical Distribution \& Logistics Management, 28(1), 44-67, doi:10.1108/09600039810205953.

Masai, Y. 1962. Central places in central Michigan, U.S.A. Geographical Review of Japan, 35(2), 53-66, doi:10.4157/grj.35.53. 
Maye, D. \& Ilbery, B. 2006. Regional Economies of Local Food Production. European Urban and Regional Studies, 13(4), 337-354, doi:10.1177/0969776406068588.

Mesarovich, M., Mako, D. \& Takahara, I. 1972. Theory of hierarchical multilevel systems. Moscow: MIR. P. 344.

Milligan, G.F. 1984. Agglomeration and central place theory: a review of the literature. International regional science review, Vol. 9, №1, 1 - 42, doi: $10.1177 / 016001768400900101$ sportsspo.

Mittal, A., Krejci, C. \& Craven, T. 2018. Logistics Best Practices for Regional Food Systems: A Review. Sustainability, 10(2), 168, doi:10.3390/su10010168.

Philbrick, A.K. 1957. Principles of Areal Functional Organization in Regional Human Geography. Economic Geography, Vol. 33, No. 4, 299 - 336.

Philbrick, A.K. 1982. Hierarchical nodality in geographical time - space. Economic Geography, Vol. 58, No. 1, 1-19.

Pissourios, I.A. \& Lagopoulos, A.P. 2017. The Classification of Urban Uses. Urban Sci, 1, 26, doi:10.3390/urbansci1030026.

Sadigh, N.A., Fallah, H. \& Nahavandi, N. 2013. A multi - objective supply chain model integrated with location of distribution centers and supplier selection decisions. The International Journal of Advanced Manufacturing Technology, 69(1 - 4), 225-235, doi: $10.1007 / \mathrm{s} 00170-013-5013-\mathrm{y}$.

Sheu, J.B. 2003. Locating manufacturing and distribution centers: An integrated supply chain - based spatial interaction approach. Transportation Research Part E: Logistics and Transportation Review, 39(5), 381-397, doi:10.1016/s1366 - 5545(03)00018 - 8.

Wu, T., Shen, H. \& Zhu, C. 2015. A multi - period location model with transportation economies - of - scale and perishable inventory. International Journal of Production Economics, 169, 343-349, doi:10.1016/j.ijpe.2015.08.018.

Yusupov, K.N., Timiryanova, V.M., Popov, D.V. \& Trofimova, N.V. 2019. Evaluar el impacto fronterizo en gestión de una unidad municipal mediante el uso de métodos de análisis jerárquico. Espacios, Vol. 40 (Number 20), P. 27.

Zhang, H., Xiong, Y., He, M. \& Qu, C. 2017. Location Model for Distribution Centers for Fulfilling Electronic Orders of Fresh Foods under Uncertain Demand. Scientific Programming, 1-13, doi:10.1155/2017/3423562. 